\title{
Culto ao corpo e exposição de produtos na mídia especializada em estética e saúde
}

\author{
Alexandre Palma de Oliveira* \\ Monique Assis ${ }^{* *}$ \\ Yara Lacerda*** \\ Marcos Bagrichevsky ${ }^{* * * *}$ \\ Karen Santana de Sampaio ${ }^{* * * * *}$
}

\begin{abstract}
Resumo: O objetivo do estudo foi investigar as estratégias discursivas presentes na revista Boa Forma e identificar o apelo mercadológico em tais discursos. A pesquisa se pautou em exames quantitativos e qualitativos. Foram adotadas análises de discurso e imagem. As informações contidas nas revistas, não raro, estimulam intervenções para transformação do corpo e os produtos a ela associados fazem parte da aposta para alcançar um padrão estético que, referendado por especialistas, subsume novas obrigações morais. Deste modo, a revista reforça a noção de culpabilização da mulher frente aos fenômenos construídos socialmente.
\end{abstract}

Palavras-chave: Publicações periódicas como assunto. Imagem corporal. Exercício. Culpa.

\section{INTRODUÇÃO}

Na perspectiva de Foucault (1999), a vida biológica é um evento político. Nos dois últimos séculos, a saúde tem se tornado cada vez mais politicamente relevante como um eixo articulador entre Estado e população. Sob este prisma, observa-se crescente ênfase discursiva

\footnotetext{
* Pós-Doutor em Organização do Trabalho e Saúde Mental. Universidade Federal do Rio de Janeiro. Programa de Pós-graduação Stricto Sensu em Educação Física Rio de Janeiro, RJ, Brasil. E-mail: palma_alexandre@yahoo.com.br

** Doutora em Educação Física. Centro Universitário Augusto Motta. Curso de Educação Física Rio de Janeiro, RJ, Brasil.E-mail: monique_assis@uol.com.br

*** Doutora em Educação Física. Universidade Estácio de Sá, Curso de Educação Física e Universidade Gama Filho, Departamento de Educação Física. Rio de Janeiro, RJ, Brasil . E-mail: yaralacerda@mls.com.br

**** Doutor em Saúde da Criança e do Adolescente. Universidade Estadual de Santa Cruz. Rio de Janeiro, RJ, Brasil. E-mail: marcos_bagrichevsky@yahoo.com.br

***** Licenciada em Educação Física. Universidade Estácio de Sá. Curso de Educação Física. Rio de Janeiro, RJ, Brasil .E-mail: krn_mail@yahoo.com.br
} 
a favor do envolvimento com (auto)disciplina e normas de comportamento na busca de se promover uma "boa saúde" (sem que necessariamente percebamos emergir, na mesma medida, discussões acerca da problematização do significado disso).

$\mathrm{Na}$ literatura científica biomédica ou em suas construções contemporâneas que ecoam na mídia, é possível encontrar uma extensa variedade de discursos advogando a relação entre "corpos em forma" e a ideia de evitar riscos à saúde. O pensamento probabilístico tem sido utilizado hegemonicamente como ferramenta fundamental de convencimento dessa relação. Segundo pesquisadores do campo das ciências da saúde, o trato matemático dos fenômenos possibilitaria o "controle" de tais riscos. Os resultados investigativos, via de regra epidemiológicos, se convergem em receituário não medicamentoso ao prescrever em certos comportamentos que, se adotados, imporiam um "estilo de vida" dito saudável às pessoas (LUPTON, 1997; CASTIEL; VASCONCELLOS-SILVA, 2006).

A prática regular de exercícios físicos, a chamada alimentação adequada e a redução da gordura corporal estão entre as preconizações que essa visão busca associar à diminuição dos riscos de doenças crônico-degenerativas, tais como doença arterial coronariana, hipertensão, diabetes, dislipidemias, depressão e osteopenia (US DEPARTMENT OF HEALTH AND HUMAN SERVICES , 1996).

Assim, a ideia de cálculo estatístico agregada às "promessas retóricas" dos especialistas vem configurando uma perigosa relação entre ciência e verdade, propagando a noção de que seria possível gerenciar o futuro de nossa saúde e de nossa vida através do pensamento racional. A simplicidade dessa visão de mundo subsume que evitemos encarar de frente as incertezas e ambiguidades do mundo atual, globalizado e cada vez mais desigual socialmente.

Em consonância com essa concepção de "comportamentos de risco", e talvez não desprovidos de interesses, certos autores ainda defendem a posição de que há em curso uma epidemia destes comportamentos e de suas consequências (MONTEIRO et al., 2003; NIELSEN; POPKIN, 2003).

Movimento, Porto Alegre, v. 16, n. 01, p. 31-51, janeiro/março de 2010. 
A ciência médica e suas dimensões correlatas, a partir desse "imperativo naturalizante" que sugere obviedade quanto aos riscos precisarem ser controlados, impõem aos indivíduos a adoção de determinados "estilos de vida", ainda que a margem de escolha em certos estratos socioeconômicos da população praticamente inexista. Nesta retórica, para aqueles sujeitos que permanecem afeitos às práticas cotidianas enquadradas como "comportamentos de risco" que ameaçam a conservação da vida, resta assumir a responsabilidade do seu eventual adoecimento e do suposto insucesso por não alcançarem a tão almejada "boa saúde" (LUPTON, 1997).

Lupton (1997) lembra que, a despeito da aura de cientificidade, os cálculos matemáticos que cercam os riscos pessoais à saúde apresentam sérias limitações preditivas e que costumam estar revestidos de outros interesses e servir de controle disciplinador dos corpos. Do mesmo modo, Campos et al. (2006) e Gard e Wright (2005) indagam se existe, de fato, uma "epidemia da obesidade", por exemplo, ou se está em jogo uma retórica alarmista, ideológica e moralista, que se coaduna com uma fartura de interesses corporativos e mercadológicos.

Por outro lado, é pertinente questionar de que forma estas informações têm chegado às pessoas e como elas as têm significado em seus cotidianos. Seguindo este caminho, Luiz (2006) realizou uma interessante investigação acerca do processo de difusão de informações científicas em jornais de grande tiragem, da construção ideológica de valores e da legitimação social dos comportamentos.

Cabe lembrar que os discursos circulantes sobre riscos à saúde (VAZ et al., 2007; SIBÍLIA, 2004) são constructos de caráter normativo e estão inapelavelmente vinculados a diferentes interesses. São constituídos, de modo explícito ou não, a partir de definições do que é ser humano, do tipo de sociedade que se almeja e as maneiras de alcançá-la.

Em outra investigação, Domingues, Araújo e Gigante (2004) verificaram que os meios de comunicação são, à frente dos médicos, a principal fonte informativa quanto aos prováveis benefícios da prática regular dos exercícios físicos. Markula (2001) destaca que as

Wovimento, Porto Alegre, v. 16, n. 01, p. 31-51, janeiro/março de 2010. 
revistas femininas de fitness, há muito tempo, exploram a imagem negativa do corpo das mulheres, como forma de persuadí-las a mudarem determinados comportamentos (que incluem consumo de vários produtos).

Do mesmo modo, Serra e Santos (2003) lembram que o fato de os meios de comunicação serem informativos não torna, necessariamente, adequado o teor das notícias divulgadas. O discurso midiático costuma, inclusive, segundo as autoras, ser ambíguo e enganoso.

Além disso, a construção imaginária contemporânea de um corpo perfeito ou ideal, muitas vezes intimamente associada a um discurso obsessivo da saúde, medicalizado, pode gerar situações de "iatrogênese", isto é, a "condição de dano ou enfermidade gerada por um procedimento de diagnóstico ou de terapia aplicado por profissional da saúde" (NOGUEIRA, 2001). Entre algumas dessas situações adversas, é possível destacar os problemas ligados à imagem corporal e, consequentemente, aos distúrbios alimentares, como anorexia e bulimia (MARKULA, 2001; MARZANO-PARISOLI, 2001).

A experiência pessoal cotidiana, entretanto, nos faz observar que a visão hegemônica de saúde permeada nos meios de comunicação fortalece e complementa a necessidade de um discurso de legitimação sociocultural, sustentada pela moral que se funda na conservação da vida. O que subjaz esta questão é a sedução constante de busca de um corpo utopicamente considerado "perfeito". Em outras palavras, o que parece impelir as pessoas a mostrar adesão à prática de exercícios físicos e a tudo a ela agregado pode residir muito mais no desejo de modelagem estética das formas corporais do que na prevenção de determinadas doenças. Todavia, não se pretende aqui julgar o que seria "certo" ou "errado" em termos de escolhas individuais.

Contudo, é preciso enfatizar que certa ordem ideológica vigente na saúde, hoje, é regulada, em grande parte, pela economia de mercado dos cosméticos, fármacos e produtos alimentícios em geral, a qual dita e propaga aquilo que pode e deve funcionar como um medicamento ou como um "bem maior" para nossa saúde; desse modo, investe no controle e na estimulação dos corpos (SANT'ANNA,

Movimento, Porto Alegre, v. 16, n. 01, p. 31-51, janeiro/março de 2010. 
2002; VIGARELLO, 2006) e na ascese de valores societários elitistas (ORTEGA, 2003).

Assim, os meios de comunicação têm veiculado representações, desejos e expectativas nos indivíduos através de notícias, informações e propagandas assentes a uma ética de mercado. A publicidade não cessa de anunciar e estimular o uso de produtos dietéticos, práticas alimentares, fitness, cosméticos e cirurgias plásticas como soluções para o corpo perfeito, o emagrecimento ou prevenção de doenças (LUIZ, 2006; VIGARELLO, 2006).

Acredita-se que a mídia, por sua extensão, formatação, penetração e por ser lugar de circulação de variados discursos, constitui uma relevante instância produtora de subjetividades contemporâneas, pode até ser pensada como "autoridade" (HENNIGEN, 2006).

Considerando a exposição deste painel de ideias, o objetivo geral do presente estudo é, então, examinar as estratégias discursivas presentes na revista Boa Forma que relacionam o estilo de vida com a estética corporal e a saúde. Os objetivos específicos são: $a$ ) esmiuçar as mensagens escritas e visuais associadas ao culto ao corpo e $b$ ) identificar os enunciados mercadológicos por trás desses discursos. A pesquisa trabalha com a produção de sentidos do discurso midiático, procurando desvelar e problematizar os saberes aí imbricados.

\section{MÉtodos}

O presente estudo caracteriza-se como sendo de natureza quantitativa e qualitativa. A princípio, procuramos quantificar as informações imagéticas e textuais contidas em cada número para que se possa extrair daí algumas reflexões. Na abordagem qualitativa, a investigação fundamentou-se na Teoria da Análise do Discurso proposta por Orlandi (1996) para tentar compreender o modo de funcionamento, os princípios de organização e as formas de produção social do sentido nas matérias selecionadas.

A análise do conteúdo visual seguiu os pressupostos teóricos de Bauer e Gaskell (2002) para explorar o(s) sentido(s) daí derivado(s),

Wovimento, Porto Alegre, v. 16, n. 01, p. 31-51, janeiro/março de 2010. 
bem como do(s) texto(s) que nele está(ão) ancorado(s). O trabalho é decifrar os sentidos que a "naturalização" aparente das imagens indica e implica.

Foram selecionados os doze números do periódico Boa Forma, publicados em 2004. Esta revista foi escolhida intencionalmente por ser aquela que talvez tenha a maior circulação dentro do espaço das academias de ginástica. Além disso, sua tiragem mensal alcança algo em torno de 225.000 exemplares vendidos em todo o território brasileiro, sendo seu maior público consumidor $(79 \%)$ constituído por mulheres entre 18 e 34 anos de idade (ANDRADE, 2003).

Todos os números foram lidos na íntegra duas vezes. O processo de análise foi constituído por diferentes etapas. Inicialmente, realizouse uma primeira leitura do material para melhor se compreender a linha do periódico e visualizar os possíveis caminhos da investigação. À segunda investida coube uma filtragem destacando os textos que apresentavam mensagens de culto ao corpo ou exposição mercadológica de produtos, além de contabilizar o total de informações sobre as estratégias para alcançar os padrões corporais desejados e de imagens dos corpos exibidos.

A partir daí foi possível selecionar os textos para o estudo e posterior análise por todos os pesquisadores. Nesta fase do trabalho os textos e imagens foram interpretados analiticamente. Posteriormente, as interpretações foram discutidas e, assim, produzida uma análise final do grupo sobre os sentidos transmitidos das mensagens escritas e visuais.

Além disso, à semelhança do estudo desenvolvido por Serra e Santos (2003), durante este processo de recorte das mensagens que interessavam, foi elaborada uma grade analítica, a qual considerou: a) o título da matéria, uma vez que os títulos chamam a atenção do leitor e funcionam como propaganda, uma fonte motivadora para a leitura dos textos; b) quem fala, na medida em que dependendo do ator social a qual a fala é atribuída, o discurso pode adquirir maior ou menor legitimidade e, assim, gerar identificação do leitor; c) o que é dito, os sentidos e significados explícitos e/ou implícitos nos discursos

Movimento, Porto Alegre, v. 16, n. 01, p. 31-51, janeiro/março de 2010. 
midiáticos relacionados à saúde, beleza e emagrecimento; d) o intermediário, aquele que enuncia o faz de acordo com o perfil editorial do veículo para o qual trabalha e este veículo encontra-se associado aos interesses de seus patrocinadores e e) os modos de dizer do discurso, isto é, a forma como a mensagem midiática se estabelece frente ao enunciado técnico-científico.

\section{APRESENTAÇÃO E DISCUSSÃO dOS RESULTADOS}

Ao que parece, os veículos de comunicação especializados em "produção dos corpos" têm exercido um fascínio e poder principalmente sobre as mulheres. A produção de sentidos é legitimada e encontra ressonância onde exatamente se busca esta reivindicação. Em outras palavras, a mídia per si não inaugura processos, não constroi imaginários, mas, antes, o leitor ou telespectador já demandava os modelos expostos ou descritos (BUCI, 2004; BRITTO, 2003). De fato, ela própria é atravessada pelos fenômenos sociais e, por conseguinte, também reprodutora destes.

Lipovetsky (2004) sustenta que embora os meios de comunicação de massa possam influenciar de algum modo a sociedade, eles não podem tudo, não têm amplos poderes. Não é de estranhar, portanto, que apesar de se viver em um momento de exacerbado culto ao corpo, contraditoriamente haja uma enormidade de pessoas que não incorpora qualquer prática de exercícios físicos no seu dia a dia, que não estabelece rotineiramente a alimentação considerada adequada pelos especialistas e, quiçá, são obesas.

Assim, é preciso considerar que o processo de produção de sentidos se faz de modo dinâmico, não linear e opera mudanças ao longo da veiculação das mensagens como observaram Serra e Santos (2003).

O total de reportagens ou informações veiculadas a respeito das estratégias para alcançar padrões corporais desejados, especialmente no que se refere aos exercícios físicos, bem como a quantidade de produtos e/ou publicidades implicitamente presentes nas mensagens podem ser visualizados na Tabela 1.

Wovimento, Porto Alegre, v. 16, n. 01, p. 31-51, janeiro/março de 2010. 


\begin{tabular}{|c|c|c|c|}
\hline \multirow{2}{*}{ Números da revista } & $\begin{array}{c}\text { Mensagens sobre } \\
\text { exercícios físicos }\end{array}$ & $\begin{array}{c}\text { Publicidade contida nas mensagens } \\
\text { sobre exercícios físicos }\end{array}$ & $\begin{array}{c}\text { Mensagens sobre } \\
\text { outros temas }^{*++}\end{array}$ \\
\cline { 2 - 4 } & $\mathbf{n}$ & $\mathbf{n}$ & $\mathbf{n}$ \\
\hline 1 & 12 & 6 & 30 \\
\hline 2 & 18 & 11 & 35 \\
\hline 3 & 10 & 7 & 35 \\
\hline 4 & 11 & 8 & 37 \\
\hline 5 & 11 & 9 & 37 \\
\hline 6 & 13 & 8 & 44 \\
\hline 7 & 6 & 3 & 30 \\
\hline 8 & 6 & 4 & 29 \\
\hline 9 & 9 & 5 & 29 \\
\hline 10 & 10 & 9 & 28 \\
\hline 11 & 9 & 5 & 34 \\
\hline 12 & 9 & 7 & \\
\hline
\end{tabular}

Tabela 1. Quantitativo de mensagens e publicidade sobre exercícios físicos relacionados à beleza ou à saúde na revista Boa Forma, por números de 2004

É interessante destacar que, das 124 mensagens encontradas sobre exercícios físicos, $82(66,12 \%)$ apresentavam algum produto associado. O papel do veículo, aqui, parece o de celebrar não só o amor ao corpo, aos prazeres, à beleza mas, principalmente, ao consumo.

Algumas das mensagens encontradas são apresentadas e discutidas a seguir. No número 1, por exemplo, foi dito por um especialista em farmácia: "na hora da compra, procure produtos com substâncias que dissolvem os nódulos endurecidos (chá verde, guaraná, hena ou cafeisilane C), que reduzem a gordura localizada (cânfora, mentol e azuleno) e ativam e melhoram a circulação (castanha da índia, centelha asiática e gingko biloba)".

Interessante destacar, ainda, outros aspectos contidos na matéria. A mensagem faz parte de uma seção da revista que, segundo o seu editorial, recebe dúvidas do leitor. Uma das questões apresentadas foi: "Qual a melhor hora de usar o creme para celulite: antes ou depois da ginástica?". Acima da pergunta aparece uma pequena chamada, destacada na cor azul ("à prova de furinhos"). A estratégia deste pequeno subtítulo é chamar a atenção das mulheres para uma das maio-

* Foram excluídas as informações provenientes de depoimentos de leitoras ou pessoas públicas (atrizes, modelos etc), assim como as matérias publicitárias.

** Foi considerado como publicidade a informação que citava nome de academias, marcas de vestuário, aparelhos físico-esportivos ou centros de tratamento. As citações de universidades ou centros de pesquisa não foram consideradas como informes publicitários.

*** Os outros temas referem-se, normalmente, à nutrição, cirurgias plásticas e cosméticos.

Movimento, Porto Alegre, v. 16, n. 01, p. 31-51, janeiro/março de 2010. 
res preocupações femininas relacionadas ao corpo e certamente funciona como uma propaganda persuasiva na leitura e interpretação da mensagem. O conteúdo informativo é avalizado por uma expertise, representante do conhecimento científico que, supostamente, garante maior legitimidade a este. A mensagem, ao oferecer também possibilidade genérica de tratamento do caso, desconsidera as diferenças genéticas ou a idade e deixa implícita a noção de que existiria um corpo perfeito ou "à prova de furinhos". Este discurso, obviamente, não é "neutro", apesar da "tarja" científica da especialista que responde pela matéria e se presta, sim, ao anúncio sutil de produtos que a farmacêutica e outras áreas costumam vender. Isto fica mais claro quando se anuncia o centro de beleza e estética da profissional.

Um segundo exemplo pode ser verificado no número 4 do periódico em questão. Na seção "papo de academia", no estilo "perguntaresposta", a chamada se dá com a questão: "Agachamento com carga dá dor nas costas?". O título da mensagem associa a realização correta do exercício com o risco de lesão. O enunciado seduz o(a) leitor(a) a ver a matéria, mesmo porque a incidência de "dor nas costas" não é baixa. Novamente, quem emite a resposta é uma especialista e, por isso, parece estar garantida a legitimidade da informação. Por outro lado, transparece uma ideia de que é preciso realizar os exercícios adequadamente e que a postura incorreta causa as dores. Implicitamente, significa dizer que seria necessário o auxílio de alguém para corrigir frequentemente a execução dos exercícios. Quem enuncia não o faz com imparcialidade e se apresenta não como professor de educação física, mas como "personal trainer", profissão que, aliás, não existe. A forma com que se manifesta também merece destaque. A primeira parte da mensagem é uma resposta rápida e aparentemente bastante segura. Em seguida, a profissional é apresentada e há mais explicações ressaltando a questão da postura.

No número 10 da revista destaca-se uma reportagem sobre a "perda de barriga". A chamada principal é na capa e vem dividida em quatro partes. A primeira trata da relação do estresse com a gordura localizada no abdômen. Posteriormente, são fornecidos dados sobre a possibilidade de massagens e injeções para atenuar o acúmulo de gordura local. A terceira matéria jornalística aborda a dieta consi-

Wovimento, Porto Alegre, v. 16, n. 01, p. 31-51, janeiro/março de 2010. 
derada mais adequada. Por fim, a última reportagem refere-se aos exercícios localizados e ao modo como devem ser feitos. No título ("abdômen desenhado por quem entende do riscado"), aparecem chamarizes importantes: inicialmente parecem incitar nos(as) leitores(as) o desejo de ter o abdômen com baixa quantidade de gordura. Segundo, sugere que quem entende, e somente ele, é que irá falar. O subtítulo destaca o fato de se fazer exercícios abdominais e não alcançar os resultados desejados. O trecho diz: "Você até pode fazer 200 abdominais por dia, mas a barriga continua aí, teimosa? O motivo? Dificilmente está exercitando o transverso, o mais profundo dos músculos abdominais. Ao contrário dos outros - oblíquos internos, externos e o reto abdominal -, ele não é trabalhado na ginástica tradicional. Em compensação, é impossível fazer qualquer movimento do pilates sem acioná-lo".

A mensagem segue se referindo ao criador do método, procurando fornecer mais explicações e apresentando a especialista que abona as informações iniciais. Mais uma vez, quem dá formato ao texto não está despojada de interesses em relação ao teor central da matéria que apresenta: é professora de (método) Pilates e proprietária de um centro de ginástica postural que o utiliza. A reportagem apresenta ainda imagens de abdômens considerados perfeitos, alimentando o imaginário dos(as) leitores(as) com a ideia de que certos exercícios permitiriam alcançar um desenvolvimento muscular perfeito, noção, esta, falaciosa.

Outra questão bastante interessante refere-se à exposição de imagens e à exacerbação do culto ao corpo a elas atreladas. A Tabela 2 apresenta uma síntese dos aspectos mais gerais destacados nas imagens presentes nas reportagens selecionadas. Foram desconsideradas aquelas referentes aos anúncios publicitários explícitos.

Cabe destacar que o quantitativo exposto na Tabela 1 expressa os padrões de corpo que a sociedade, em especial o grupo feminino, supostamente deseja conquistar e que norteiam as ações em direção às dietas, às práticas de exercícios físicos e às cirurgias plásticas. Além disso, predomina a aparição dos corpos por inteiro, uma vez que a cabeça retratada separadamente parece ser associada mais à intelectualidade (GOLDENBERG; RAMOS, 2002).

Movimento, Porto Alegre, v. 16, n. 01, p. 31-51, janeiro/março de 2010. 


\begin{tabular}{|c|c|c|c|c|c|c|c|c|c|c|c|c|c|}
\hline \multirow{2}{*}{$\begin{array}{c}\text { Números da } \\
\text { revista }\end{array}$} & \multirow{2}{*}{$\begin{array}{c}\text { Número de } \\
\text { imagens }\end{array}$} & \multicolumn{2}{|c|}{ Gênero } & \multicolumn{3}{|c|}{ Raça } & \multicolumn{3}{c|}{$\begin{array}{c}\text { \% de gordura } \\
\text { aparente }\end{array}$} & \multicolumn{3}{|c|}{ Faixa etária } & \multicolumn{2}{|c|}{ Parte do corpo } \\
\cline { 3 - 16 } & & $\mathbf{M}$ & $\mathbf{F}$ & $\mathbf{B r}$ & $\mathbf{N e}$ & $\mathbf{A L}$ & $\mathbf{B X}$ & $\mathbf{C}$ & $\mathbf{J}$ & $\mathbf{M D}$ & $\mathbf{I}$ & $\mathbf{C I}$ & $\mathbf{R}$ \\
\hline 1 & 121 & 4 & 117 & 120 & 1 & 7 & 114 & 0 & 104 & 17 & 0 & 100 & 21 \\
\hline 2 & 109 & 10 & 99 & 108 & 1 & 8 & 101 & 0 & 97 & 6 & 6 & 85 & 24 \\
\hline 3 & 145 & 8 & 137 & 145 & 0 & 4 & 141 & 1 & 142 & 1 & 1 & 105 & 40 \\
\hline 4 & 208 & 19 & 189 & 208 & 0 & 17 & 191 & 0 & 202 & 6 & 0 & 174 & 34 \\
\hline 5 & 153 & 11 & 142 & 152 & 1 & 12 & 141 & 0 & 152 & 1 & 0 & 124 & 29 \\
\hline 6 & 128 & 7 & 121 & 125 & 3 & 7 & 121 & 0 & 126 & 2 & 0 & 110 & 38 \\
\hline 7 & 120 & 12 & 108 & 119 & 1 & 13 & 107 & 0 & 112 & 8 & 0 & 100 & 20 \\
\hline 8 & 143 & 1 & 142 & 142 & 1 & 16 & 127 & 0 & 138 & 5 & 0 & 101 & 42 \\
\hline 9 & 125 & 8 & 117 & 123 & 2 & 12 & 113 & 0 & 118 & 5 & 2 & 104 & 21 \\
\hline 10 & 142 & 4 & 138 & 142 & 0 & 13 & 129 & 0 & 132 & 10 & 0 & 119 & 23 \\
\hline 11 & 125 & 5 & 120 & 121 & 4 & 10 & 115 & 0 & 122 & 3 & 0 & 105 & 20 \\
\hline 12 & 134 & 5 & 129 & 128 & 6 & 2 & 132 & 0 & 132 & 1 & 1 & 91 & 43 \\
\hline
\end{tabular}

Tabela 2. Distribuição dos aspectos presentes nas imagens corporais

Legenda: Gênero ( $\mathrm{M}=$ masculino e $\mathrm{F}=$ feminino); $\operatorname{Raça~}(\mathrm{Br}=$ branco e $\mathrm{Ne}=$ negro); $\%$ de gordura aparente $(\mathrm{AL}=$ alto e $\mathrm{BX}=$ baixo $)$;

Faixa etária $(\mathrm{C}=$ criança, $\mathrm{J}=$ jovem entre 18 e 30 anos, $\mathrm{MD}=$ maduro acima de 30 anos até aproximadamente 50 anos e I = idoso acima 50 anos) e

Parte do corpo $(\mathrm{CI}=$ corpo inteiro e $\mathrm{R}=$ rosto $)$.

Fotos de mulheres jovens aparecem em maior número, como era de se esperar (considerando o perfil da revista). Obviamente, entre estas se destacam as pessoas com baixa quantidade de gordura corporal e dentro de padrões estéticos utópicos estimulados e cobiçados. Por outro lado, as expressões visuais referentes ao alto percentual de gordura são de sujeitos da equipe da revista ou de mensagens do tipo "antes e depois", onde o indivíduo aparece com percentual de gordura elevado (antes) e posteriormente, após se submeter a uma dieta e/ou programa de exercícios físicos, apresenta-se dentro de modelos corporais recomendados pela revista (depois). A difusão imagética de tipos ideais de corpo, como a magreza, pode significar status social e favorecer mudanças comportamentais ou determinadas intervenções (MARKULA, 2001; BRITTO, 2003). Não à toa tem crescido o número de cirurgias plásticas em todo mundo (MARZANO-PARISOLI, 2001).

A cor da pele parece ser também algo relevante para os editores da revista. Das 1.633 imagens corporais identificadas, somente 20 $(1,22 \%)$ eram de pessoas de fenótipo negro. Os retratos das moças na capa da revista obviamente caminham na mesma direção, isto é, só foram estampadas as de tez clara.

Movimento, Porto Alegre, v. 16, n. 01, p. 31-51, janeiro/março de 2010. 
Bauer e Gaskell (2002) comentam que o sentido de uma imagem é ancorado pela condição da qual gozam os "objetos". No presente caso, pode-se refletir sobre o status social dos corpos. Goldenberg e Ramos (2002) enfatizam que os "corpos-padrões" representam o investimento na força de vontade e autodisciplina. Além disso, destacam a nova moralidade que "patrulha" os "erros corporais" ou de vestimenta (em função de se distanciarem de normas ascéticas criadas e impostas subjetivamente). Neste sentido, a gordura significa desleixo, preguiça ou doença. Por outro lado, Farias (2002) salienta que a pele bronzeada na cidade do Rio de Janeiro parece ser o sinônimo de beleza e saúde em contraste com a cor branca e negra. Não por acaso o destaque na capa do número 3 é: "dourada o ano todo".

Duerksen et al. (2005), em uma investigação com revistas femininas norte-americanas, verificaram que, comparados aos indivíduos brancos, os negros tinham suas fotografias mais associadas às mensagens potencialmente nocivas à saúde. Mesmo nas revistas destinadas aos indivíduos desse grupo étnico, muitas informações em saúde mantinham-se relacionadas ao impacto negativo.

A utilização das expressões visuais pela revista Boa Forma foi sempre muito semelhante e, portanto, as escolhas de algumas poucas nos serviram para exemplificar o caráter que elas assumem. Na análise da imagem da capa do número de abril foi verificado o sistema semiológico que sustentava a comunicação. O retrato estampado trazia ali uma famosa atriz de uma poderosa emissora de televisão, bastante elogiada na mídia por sua beleza. Fotografando de biquíni, ela expõe intencionalmente seu abdômen, para que fique em destaque o baixo percentual de gordura e seu "corpo invejável". A imagem é ancorada por um texto que enuncia: "musculação, hip-hop e alegria: a fórmula mágica de [...]". Mais abaixo na revista, anunciando uma outra reportagem, um texto curto mas chamativo: "tudo para sua transformação". A comunicação visual como um todo parece sugerir soluções mágicas e rápidas para transformar os corpos. Bauer et al. (2002) explicam que, de um modo geral, as imagens são paradoxais ou polissêmicas e que, por isso, precisam estar acompanhadas de alguma ancoragem, isto é, como estratégia, o texto busca minimizar ou suprimir a ambiguidade que a imagem, supostamente, suscita.

Movimento, Porto Alegre, v. 16, n. 01, p. 31-51, janeiro/março de 2010. 
Gonçalves Júnior (2003) corrobora esta posição ao afirmar que as mensagens sobre exercícios físicos, dietas, corpos e modelos de beleza contidas nos meios de comunicação estão em conformidade com a rapidez de informação da vida contemporânea e que tudo é vendido como uma questão de vontade, como sendo fácil, rápido e sem sacrifícios.

No número de julho pode-se observar o "desafio do clube da gordinha". A proposta era verificar o quanto dez moças reduziram seus respectivos Índices de Massa Corporal (IMC), isto é, a divisão do peso (em Kg) pelo quadrado da estatura (em m), inicialmente entre 22,10 e 39,45, alcançando o objetivo denominado de "peso dos sonhos". Interessante ressaltar que as fotografias das modelos ou atrizes das capas mereceram atenção destacada no corpo da revista, apresentando o IMC variando entre 18,37 e 19,83 (média = 19,10 e desvio padrão $=0,51)$, todas classificadas com massa corporal abaixo do índice de magreza, considerado normal segundo os padrões preconizados pela Organização Mundial da Saúde. As medidas antropométricas informadas pela revista possibilitavam calcular o índice de androgenia, que revela a tendência de um corpo mais "tubular". Os valores (média $=0,74$ e desvio padrão $=0,07$ ) mostraram uma inclinação semelhante aos dos estudos de Voracek e Fisher (2002) e Britto (2003).

Os retratos das moças do "clube da gordinha", portanto, diferem muito das imagens femininas mais frequentes da revista. Das dez jovens, sete fotografam de calças compridas e blusas de mangas longas, deixando à mostra somente o rosto. Duas delas vestiam blusas com mangas compridas até a articulação do cotovelo. Somente uma apresentava os braços descobertos. Contudo, nas duas páginas de abertura da reportagem todas estavam completamente cobertas. "Estar coberta" pode sugerir que escondiam as "imperfeições", a "inadequação" do corpo (interpretadas como "erros de conduta" em relação aos cuidados de si). Goldenberg et al. (2002) complementam, nessa direção, que é socialmente construída e aceita a ideia da inconveniência de se expor um corpo fora dos padrões estéticos considerados ótimos.

A obsessão pela conquista de um padrão de beleza próximo àquele que é disseminado com veemência pela mídia faz com que os simpatizantes do universo do fitness se familiarizem acerca da

Wovimento, Porto Alegre, v. 16, n. 01, p. 31-51, janeiro/março de 2010. 
"necessidade" de se livrar, a qualquer custo, do excesso de gordura corporal, pois os gordos, segundo Fischler,

\begin{abstract}
“[...] são considerados transgressores; eles parecem violar constantemente as regras que governam o comer, o prazer, o trabalho e o esforço, a vontade e o controle de si. Dito de outro modo, o obeso (seu corpo o trai) passa por alguém que come mais do que os outros, mais do que o normal, numa palavra: mais do que a sua parte.” (FISCHLER, 1995, p. 74).
\end{abstract}

Abaixo de cada fotografia há textos de apresentação das jovens. Estes escritos reforçam a obesidade como decorrente de um problema de saúde, mas também da preguiça ou da gula: "engordei muito por causa de um problema na tiróide", "engordei bastante graças a minha ansiedade e insegurança", "resolvi me cuidar", "o grupo vai garantir o incentivo de que preciso para dar a volta por cima", "meu ponto fraco são os doces", "relaxei com a alimentação". Mais abaixo de cada par de páginas, as mensagens em letras maiores enunciam: "bem-vinda ao desafio do clube da gordinha" e "a batalha contra a balança começa aqui! Pegue carona". A mensagem, como um todo, indica ojeriza ao corpo obeso que necessita ser modificado, metamorfoseado (MARKULA, 2001; MARZANO-PARISOLI, 2001).

Em estudo sobre o papel das revistas femininas na distorção da imagem corporal, Markula (2001) salienta que tais veículos reforçam a noção de culpabilização do sujeito frente à sua doença ou aos seus problemas relacionados à saúde. Para o autor, as mensagens tratam os distúrbios de modo comum, apenas como problemas biológicos, de responsabilidade de cada indivíduo e desvinculados das questões políticas, sociais, econômicas e culturais. Ainda segundo este pesquisador, os periódicos se valem do discurso médico-científico para seu próprio ganho comercial.

Na fabricação do corpo, o mercado é inesgotável. Marx (1996, p. 32) aponta que a produção não se limita a fornecer um objeto material à necessidade, mas antes fornece uma necessidade ao objeto material e completa: "a produção não cria somente um objeto para o sujeito, mas também um sujeito para o objeto". Isto explica como a vigilância sobre o próprio corpo e saúde tem implicado em um elevado

Movimento, Porto Alegre, v. 16, n. 01, p. 31-51, janeiro/março de 2010 
consumo de inúmeros produtos, desde os alimentos dietéticos até os gastos com academias de ginástica, passando pelos produtos farmacêuticos, equipamentos esportivos, cirurgias plásticas, revistas especializadas etc. E, uma vez que o estilo de vida organizado em torno da busca e exaltação da boa forma é uma promessa que nunca encontra seu triunfo, o mercado e consumo da beleza se reafirmam.

Segundo Lefèvre (1991), para se oferecer a saúde como mercadoria, é preciso que se amplie o seu grau subjetivo de necessidade. Ademais, é importante que tal necessidade seja percebida como algo natural, abstrato, igual para todas as classes sociais. A publicidade, propaganda e marketing, através dos meios de comunicação de massa, completam a corrente que liga o processo de produção dessas mercadorias ao de criação dos desejos e aspirações de se obtê-las.

Como lembra Novaes (2006), o discurso biomédico tem funcionado como um regime disciplinar, uma vez que faz circular um saber/ poder inacessível ao sujeito comum, além de desencadear uma regulação social através das noções de saúde e de padrões estéticos do corpo. Vigiar e punir os indivíduos não adequados às normas, os que não se enquadram entre os tipos ideais. A autora lembra, inclusive, que a magreza e a beleza são os melhores capitais e, portanto, mais eficazes para inclusão social e valor de troca.

Por outro lado, para Deleuze (1996), há em curso uma mudança no modelo de sociedade. Se outrora vigorava uma sociedade identificada por Foucault como "disciplinar", é possível afirmar que atualmente nos deparamos com uma outra, designada por Deleuze como "sociedade de controle", embora, por certo, o momento atual seja de transição ou hibridização entre tais modelos (consequentemente, a primeira não deixou de existir). Nesse sentido, ao que parece, distancia-se de uma forma de "aprisionamento" completo para se aproximar de uma espécie de (auto)controle aberto e contínuo.

Se na sociedade disciplinar o poder se manifestava, principalmente, através da vigilância e punição e, por conseguinte, do julgamento e do medo, a sociedade de controle caracteriza-se pela invisibilidade dos poderes e envolve a subjetividade dos indivíduos, os quais são levados a nunca terminarem nada e precisarem estar em

Wovimento, Porto Alegre, v. 16, n. 01, p. 31-51, janeiro/março de 2010. 
permanente formação. Deleuze (1996) ainda explica que as instituições disciplinares são moldes, mas os controles são uma modulação, que se autodeformam e mudam a cada instante. Neste sentido, o aspecto disciplinar não desapareceu, apenas alterou o feitio de atuar e se intensificou. A disciplina passou a ser incorporada pelos sujeitos de tal modo que estes assumiram os dispositivos de poder, a despeito da presença de alguma autoridade investida. Agora, o poder é exercido por intermédio de mecanismos que estruturam diretamente o sujeito, através dos sistemas de comunicação e de informação, por exemplo, e se estende pelas profundezas da consciência (HARDT; NEGRI, 2001). Não sem razão, de acordo com Deleuze (1996), o marketing é o instrumento emergente desse novo tipo de controle social.

Segundo argumenta Veiga-Neto (2003, p. 140), "uma das consequências mais marcantes de tal mudança se manifesta nas formas pelas quais nos subjetivamos: de uma subjetivação em que a disciplinaridade é central [...] está-se passando para uma subjetivação aberta e continuada - na qual o que mais conta são os fluxos permanentes que, espalhando-se por todas as práticas e instâncias sociais, ativam-nos, fazem-nos participar e nos mantêm sob controle."

O próprio Foucault (1993) já anunciara que, se o poder tivesse apenas a função de reprimir, através da censura, da exclusão ou do impedimento, isto é, caso se manifestasse somente de modo negativo, ele seria muito frágil. Sua força se estabelece porque produz efeitos positivos no nível do desejo. E no caso das revistas das "boas formas", o poder capilariza-se de modo permeável e quase invisível, como um veículo que não cessa de afirmar que a mulher pode ser bela, se assim o quiser.

\section{CONSIDERAÇÕES FINAIS}

O presente trabalho buscou realizar um estudo sobre a análise das mensagens e imagens contidas na revista apresentadas nos números da revista Boa Forma do ano de 2004.

De modo geral, foi possível perceber que as mensagens de intervenções para transformação do corpo não cessam de ser lembradas

Movimento, Porto Alegre, v. 16, n. 01, p. 31-51, janeiro/março de 2010. 
e estimuladas.Nesse sentido, a prática regular de exercícios físicos e os produtos a ela associados fazem parte da aposta para alcançar a perfeição estética.

As informações são mediadas por especialistas (profissionais de educação física, médicos, nutricionistas, entre outros) que avalizam, orientam as estratégias e, assim, determinam as novas obrigações morais. Mais do que um plano estético, está em jogo um compromisso ético. É desta forma que o indivíduo torna-se insatisfeito com sua aparência e o mercado da atividade físico-esportiva tem crescido.

Por fim, é interessante ressaltar que se a baixa prática de exercícios físicos e a obesidade estão atreladas a uma premissa moral, a qual designa o sujeito como preguiçoso, desleixado ou irresponsável, por outro lado, as promessas encontradas na revista engendram soluções rápidas e "miraculosas", expressas nos incessantes e renováveis tipos de treinamento físico, dietas, cirurgias e produtos farmacêuticos recomendados, quase sempre inacessíveis a maior parte da população brasileira porque demandam tempo livre disponível, recursos financeiros e algum nível de conhecimento técnico pregresso.

Malysse (2002, p. 102) afirma que se as revistas só pregam o modo de vida das classes dominantes e um modelo de comportamento corporal que remete às camadas superiores da hierarquia social brasileira, nem por isso são menos lidas pelas mulheres das classes populares: "[...] as representações da corpolatria circulam por toda a sociedade brasileira".

Movimento, Porto Alegre, v. 16, n. 01, p. 31-51, janeiro/março de 2010. 
48 Artigos Originais Alexandre Palma de Oliveira et al.

Body worship and over media exposition of
products related to health and esthetics
Abstract: The aim of the present study is to understand
Boa Forma Magazine's discourse strategies that relate
physical exercise with health and esthetics and the implicit
market purposes behind its discourse. In order to reach
the objectives this study used a qualitative (discourse
and image analysis) and a quantitative approach. Results
showed that the magazine's information promotes an
encouragement to reshape the body through the practice
of physical exercises and the consumption of products
many times prescribed by experts. Therefore, it is possible
to conclude that the magazine strengthens not only
problems related to body image, but also the idea that
women are guilty for not following patterns morally
determined by society.
Keywords: Periodicals as Topic. Body image. Exercise.
Guilt.

El culto al cuerpo y la exposición de productos en los medios de comunicación especializados en estetica y salud.

Resumen: El objetivo del estudio fue investigar las estrategias de discurso presentes en la revista "Boa Forma" e identificar el recurso mercadológico existente en tales discursos. La investigación tuvo como base exámenes de cantidad y calidad. Fueron adoptados análisis de discurso y de imagen. Las informaciones contenidas en las revistas, casi siempre, estimulan intervenciones para la transformación del cuerpo y los productos asociados a ella forman parte de la apuesta para alcanzar un padrón estético que, autenticado por los especialistas, envuelve nuevas obligaciones morales. Así, la revista refuerza la noción de culpabilización de la mujer frente a los fenómenos construidos socialmente. Palabras clave: Publicaciones periódicas como asunto. Imagen corporal. Ejercicio. Culpa.

\section{REFERÊNCIAS}

ANDRADE, Sandra dos Santos. Mídia impressa e educação de corpos femininos. In: LOURO, Guacira Lopes; NECKEL, Jane Felipe; GOELLNER, Silvana Vilodre. Corpo, gênero e sexualidade: um debate contemporâneo na educação. Petrópolis: Vozes, 2003. p. $108-23$.

Movimento, Porto Alegre, v. 16, n. 01, p. 31-51, janeiro/março de 2010. 
BAUER, Martin W.; GASKELL, George. Pesquisa qualitativa com texto, imagem e som: um manual prático. Petrópolis: Vozes, 2002.

BRITTO, Pedro M. A evolução midiática do belo: transformações e tendências da estética do corpo feminino na sociedade contemporânea. 2003. Dissertação (Mestrado) - Curso de Comunicação Social, Universidade Metodista de São Paulo. São Paulo, 2003.

BUCl, Eugênio. A crítica de televisão. In: BUCl, Eugênio; KEHL, Maria Rita. Videologias: ensaios sobre televisão. São Paulo: Boitempo, 2004. p. 28-42.

CAMPOS, Paul et al. The epidemiology of overweight and obesity: public health crisis or moral panic? International Journal of Epidemiology, London, v. 35, p. 55-60, 2006.

CASTIEL, Luis David; VASCONCELLOS-SILVA, Paulo Roberto. Anoção "estilo de vida" em promoção de saúde: um exercício crítico de sensibilidade epistemológica. In: BAGRICHEVSKY, Marcos et al. A saúde em debate na Educação Física. Blumenau: Nova Letra, 2006. v. 2. p. 67-90.

DELEUZE, Gilles. Conversações. Rio de Janeiro: Editora 34, 1996.

DOMINGUES, Marlos Rodrigues; ARAÚJO, Cora Luiza Pavin; GIGANTE, Denise Petrucci. Conhecimento e percepção sobre exercício físico em uma população adulta urbana do sul do Brasil. Cadernos de Saúde Pública, Rio de Janeiro, v. 20, n. 1, p. 204-15, 2004.

DUERKSEN, Susan C. et al. Health disparities and advertising content of women's magazines: a cross-sectional study. BMC Public Health, London, v. 5, p. 85-94, 2005.

FARIAS, Patrícia. Corpo e classificação de cor numa praia carioca. In: GOLDENBERG, Mirian. Nu e vestido: dez antropólogos revelam a cultura do corpo carioca. Rio de Janeiro: Record, 2002. p. 263-302.

FISCHLER,C. Obeso benigno, obeso maligno. In: SANT'ANNA, Denise B. Políticas do corpo. São Paulo: Estação Liberdade, 1995. p. 69-80.

FOUCAULT, Michel. Microfísica do poder. Rio de Janeiro: Graal, 1993. 1999

História da sexualidade I: a vontade de saber. 13. ed. Rio de Janeiro: Graal,

GARD, Michael; WRIGHT, Jan. The obesity epidemic: science, morality and ideology. London: Routledge, 2005.

GOLDENBERG, Mirian; RAMOS, Marcelo S. A civilização das formas: o corpo com valor. In: GOLDENBERG, Mirian. Nu e vestido: dez antropólogos revelam a cultura do corpo carioca. Rio de Janeiro: Record, 2002. p. 19-40.

GONÇALVES JÚNIOR, Luiz. Cultura corporal: alguns subsídios para sua compreensão na contemporaneidade. São Carlos: EdUFSCar, 2003.

Movimento, Porto Alegre, v. 16, n. 01, p. 31-51, janeiro/março de 2010. 


\section{Astigos Origimais Alexandre Palma de Oliveira et al.}

HARDT, Michael; NEGRI, Antonio. Império. Rio de Janeiro: Record, 2001.

HENNIGEN, I. Subjetivação como produção cultural. Psicologia e Sociedade, São Paulo, v. 18, n. 2, p. 47-53, 2006.

LEFÈVRE, Fernando. O medicamento como mercadoria simbólica. São Paulo: Cortez, 1991

LIPOVETSKY, Gilles. Metamorfoses da cultura liberal: ética, mídia e empresa. Porto Alegre: Sulina, 2004

LUIZ, Olinda do Carmo. Ciência e risco à saúde nos jornais diários. São Paulo: Annablume, 2006.

LUPTON, Deborah. The imperative of health: public health and the regulated body London: Sage, 1997

MALYSSE, S. Em busca dos (H)alteres-ego: olhares franceses nos bastidores da corpolatria carioca. In: GOLDENBERG, M. Nu e vestido: dez antropólogos revelam a cultura do corpo carioca. Rio de Janeiro: Record, 2002. p. 79-138.

MARKULA, Pirkko. Beyond the perfect body: women's body image distortion in fitness magazine discourse. Journal of Sport \& Social Issues, Boston, v. 25, n. 2, p. 15879,2001

MARX, Karl. Para a crítica da economia política. In: Os PENSADORES. São Paulo: Nova Cultural, 1996, p. 25-254

MARZANO-PARISOLI, Maria M. The contemporany construction of a perfect body image: bodybuilding, exercise addiction, and eating disorders. Quest, Champaign, v. 53, n. 2 , p. $216-30,2001$

MONTEIRO, Carlos A. et al. A descriptive epidemiology of leisure-time physical activity in Brazil, 1996-1997. Revista Panamericana de Salud Publica, Washington, v. 14 n. 4, p. 246-254, 2003.

NIELSEN, Samara J.; POPKIN, Barry M. Patterns and trends in food portion sizes, $1977-$ 1998. The Journal of the American Medical Association (JAMA), Chicago, v. 289 , n. 4 , p. $450-3,2003$

NOGUEIRA, Roberto P. Higiomania: a obsessão com a saúde na sociedade contemporânea. In: VASCONCELOS, Eymard M. A saúde através das palavras e do gesto: reflexões da rede de educação popular e saúde. São Paulo: Hucitec, 2001. p. 63-72.

NOVAES, Joana V. O intolerável peso da feiúra. Rio de Janeiro: Ed. PUC-Rio/ Garamond, 2006.

ORLANDI, Eni P. Discurso e leitura. Campinas: Cortez, 1996.

ORTEGA, F. Práticas de ascese corporal e constituição de bioidentidades. Caderno Saúde Coletiva, Rio de Janeiro, v. 11, n. 1, p. 59-77, 2003.

Vovimento, Porto Alegre, v. 16, n. 01, p. 31-51, janeiro/março de 2010. 
SANT'ANNA, Denise B. Transformações do corpo: controle de si e uso dos prazeres. In: RAGO, Margareth; ORLANDI, Luiz B. L.; VEIGA-NETO, Alfredo. Imagens de Foucault e Deleuze: ressonâncias nietzschianas. Rio de Janeiro: DP\&A, 2002, p. 99-110.

SERRA, Giane M. A.; SANTOS, Elizabeth M. Saúde e mídia na construção da obesidade e do corpo perfeito. Ciência \& Saúde Coletiva, Rio de Janeiro, v. 8, n. 3, p. 691-701, 2003.

SIBILIA, P. Tiranias do "software humano": redefinições de saúde e doença. Logos, Rio de Janeiro, v. 11, n. 20, p. 41-60, 2004.

VAZ, Paulo et al. O fator de risco na mídia. Interface, Botucatu, v. 11, n. 21, p. 145-53, 2007.

VEIGA-NETO, Alfredo. Foucault \& educação. Belo Horizonte: Autêntica, 2003.

VORACEK, Martin; FISHER, Maryanne L. Shapely centrefolds? Temporal change in body measures: trend analysis. BMJ, London, v. 325, p. 1447-48, 2002.

VIGARELLO, Georges. História da beleza. Rio de Janeiro: Ediouro, 2006.

US DEPARTMENT OF HEALTH AND HUMAN SERVICES. Physical activity and health: a report of the surgeon general. Atlanta, GA: US Department of Health and Human Services, Centers for Disease Control and Prevention, National Center for Chronic Disease prevention and Health Promotion, 1996.

Wovimento, Porto Alegre, v. 16, n. 01, p. 31-51, janeiro/março de 2010 